\title{
Differences in bone structure between rheumatoid arthritis and psoriatic arthritis patients relative to autoantibody positivity
}

\author{
Roland Kocijan, ${ }^{1,2}$ Stephanie Finzel, ${ }^{1}$ Matthias Englbrecht, ${ }^{1}$ Klaus Engelke, ${ }^{3}$ \\ Juergen Rech, ${ }^{1}$ Georg Schett ${ }^{1}$
}

\begin{abstract}
Handling editor Tore K Kvien
- Additional material is published online only. To view please visit the journal online (http://dx.doi.org/10.1136/ annrheumdis-2013-203791).

${ }^{1}$ Department of Internal Medicine 3 and Institute of Clinical Immunology, University of Erlangen-Nuremberg, Erlangen, Germany

${ }^{2}$ St. Vincent Hospital - Medical Department II, The VINFORCE

Study Group, Academic Teaching Hospital of Medical University of Vienna, Austria ${ }^{3}$ Institute of Medical Physics, University of ErlangenNuremberg, Erlangen, Germany
\end{abstract}

\section{Correspondence to} Professor Georg Schett, Department of Internal Medicine 3, Rheumatology and Immunology, University of Erlangen-Nuremberg, Ulmenweg 18, Erlangen D-91054, Germany; georg.schett@uk-erlangen.de

Received 15 April 2013 Revised 5 July 2013 Accepted 15 July 2013 Published Online First 7 August 2013

\section{ABSTRACT}

Objective To investigate whether trabecular and cortical bone structure differ between patients with rheumatoid arthritis (RA) and psoriatic arthritis (PsA). So far, no study has performed a detailed comparative analysis of bone structure in patients with RA and PsA. Methods 110 patients (60 RA, 50 PsA) received highresolution peripheral quantitative $\mathrm{CT}$ of the distal radius. Demographic and disease-specific parameters including anti-rheumatic treatment, bone erosion status and previous fractures were recorded.

Results RA and PsA patients were comparable in age, gender, body mass index, disease duration, disease activity, functional status, antirheumatic treatment and bone erosion status. No significant differences were found for volumetric bone mineral density (BMD), including total BMD $\left(300 \pm 77\right.$ vs $\left.316 \pm 62 \mathrm{mgHA} / \mathrm{cm}^{3}\right)$, trabecular BMD $\left(152 \pm 46\right.$ vs $\left.165 \pm 40 \mathrm{mgHA} / \mathrm{cm}^{3}\right)$ and cortical BMD $\left(787 \pm 113\right.$ vs $\left.818 \pm 76 \mathrm{mgHA} / \mathrm{cm}^{3}\right)$ when comparing RA patients to PsA patients, respectively. However, in contrast to seronegative RA, seropositive RA showed significantly reduced trabecular BMD $(p=0.007)$, bone volume per tissue volume $(p=0.007)$ and trabecular number $(p=0.044)$, as well as a strong trend towards higher trabecular inhomogeneity compared to PsA patients. In the regression analysis, higher age, female gender and presence of autoantibodies were independently associated with trabecular bone loss. Conclusions Seropositive RA exhibits more profound changes in trabecular bone architecture than seronegative RA or PsA. The data support the concept that seropositive RA is a disease entity that is distinct from seronegative RA and PSA.

\section{INTRODUCTION}

Rheumatoid arthritis (RA) and psoriatic arthritis (PsA) are chronic inflammatory joint diseases characterised by bone destruction. ${ }^{1-3}$ Chronic synovitis occurs in RA as well as in PsA. Synovitis elicits bone erosion by inducing the differentiation of bone-resorbing osteoclasts. ${ }^{4} 5$ PsA is additionally characterised by pronounced inflammation at enthesial sites, where bone is also directly exposed to inflammatory tissue. ${ }^{6}$ Despite some similarities, considerable differences exist between RA and PsA regarding pathogenesis, clinical presentation and radiographic changes, ${ }^{7-9}$ and findings in RA can not necessarily be translated to PsA.

Apart from local bone destruction, inflammatory diseases like RA and PsA have the potential to disturb bone homeostasis on the systemic level. Even minor chronic increases of inflammatory activity can trigger systemic bone loss. ${ }^{10}$ Bone mineral density (BMD) is significantly decreased in RA patients compared to controls ${ }^{11}$ and the risk of fracture is increased at vertebral ${ }^{12}$ and peripheral skeletal sites. ${ }^{13}$ High disease activity is an independent predictor of bone loss in RA. ${ }^{14}$ Furthermore, high $\mathrm{C}$ reactive protein level, long disease duration and high radiographic erosion scores have been identified as predictors for vertebral fractures in RA patients. ${ }^{15-18}$

Far less is known about BMD changes and fracture risk in PsA patients. One study has shown decreased BMD in PsA patients compared to healthy controls, ${ }^{19}$ whereas other studies found no major differences. ${ }^{20} 21$ One possible explanation for 'normal' BMD in PsA could be pathological bone deposition along periosteal sites. ${ }^{21}$ Considering the similarities between spondylarthritis and PsA, the observation of a high prevalence of vertebral fractures in early $\mathrm{PsA}^{22}$ supports the concept that bone loss is a feature of RA and of PsA. Surprisingly, no study has yet compared the trabecular bone architecture of RA and PsA. Therefore, we aimed to perform a detailed comparative analysis of bone in RA and PsA patients by assessing volumetric BMD (vBMD) as well as trabecular and cortical microstructure at the distal radius. High-resolution peripheral quantitative CT (HR-pQCT) was used as a non-invasive imaging method that permits in vivo three-dimensional characterisation of bone microarchitecture and the assessment of vBMD for the total, trabecular and cortical bone. ${ }^{23}$ HR-pQCT has already been used with good sensitivity to detect periarticular bone changes in arthritis patients. ${ }^{24} 25$ Differences in the periarticular bone between RA and PsA have been documented in the metacarpophalangeal (MCP) joints by HR-pQCT. ${ }^{26}$ Detailed characterisation of bone quantity and bone quality can more easily and reliably be accomplished at the distal radius, which contains a larger trabecular network compared to MCP joints, allowing reliable calculation of bone microstructure by established algorithms. ${ }^{27}$

\section{METHODS}

\section{Patients and study design}

A total number of 110 patients, specifically 60 patients with RA (33 women, 27 men) and 50 patients with PsA (24 women, 26 men), were 
recruited at the Department of Internal Medicine 3 of the University of Erlangen-Nuremberg. RA patients fulfilled the 2010 American College of Rheumatology/European League Against Rheumatism classification criteria for RA, ${ }^{28}$ and PsA patients fulfilled the Classification of Psoriatic Arthritis criteria. ${ }^{29}$ Patients with RA and PsA were enrolled consecutively. RA patients were divided into seropositive RA (anticyclic citrullinated peptide antibody (ACPA)-positive and/or rheumatoid factor-positive, $\mathrm{RA}[+], \mathrm{n}=38)$ and seronegative $\mathrm{RA}(\mathrm{RA}[-]$, $\mathrm{n}=22$ ) patients. The study was approved by the local ethics committee and the national radiation safety agency (Bundesamt fuer Strahlenschutz). Subjects were enrolled in the study after agreeing to participate and signing informed consent forms. The study was performed in accordance with the Declaration of Helsinki.

Disease duration, disease activity according to the Disease Activity Score 28 (DAS28), C reactive protein level and ACPA as well as rheumatoid factor (RF) positivity were determined in all patients. Current and previous use of high-dose oral glucocorticoids ( $\geq 7.5 \mathrm{mg}$ prednisolone equivalent daily for $\geq 3$ months), low-dose oral glucocorticoids ( $\leq 5 \mathrm{mg}$ prednisolone equivalent daily for $\geq 3$ months), conventional disease-modifying antirheumatic drugs (DMARDs: methotrexate, leflunomide, hydroxychloroquine, sulfasalazine) and biologic DMARDs (tumour necrosis factor (TNF)- $\alpha$-inhibitors, abatacept, rituximab and tocilizumab) and bisphosphonates (oral and intravenous) were recorded. In addition, the functional status of all patients according to the Health Assessment Questionnaire (HAQ) as well as fracture history was documented.

\section{High-resolution peripheral quantitative CT}

HR-pQCT measurements were performed by an XtremeCT scanner (Scanco, Brüttisellen, Switzerland) at the distal radius of the clinically more affected arm using the manufacturer's standard in vivo protocol. The reference line was set manually. The first CT slice was $9.5 \mathrm{~mm}$ proximal to the reference line. For scanning, the hand was immobilised in a carbon fibre cast. An antero-posterior scout view was then used to determine the volume of interest; 110 slices (voxel size $82 \mu \mathrm{m}$ ) were then carried out. Details of the HR-pQCT measurements of the distal radius have been previously described elsewhere. ${ }^{23}$ All measurements were performed with the standard analysis software. Daily cross-calibrations with standardised control phantoms (Moehrendorf, Germany) were conducted to standardise measurements.

vBMD including total BMD $\left(\mathrm{mgHA} / \mathrm{cm}^{3}\right)$, trabecular BMD (Dtrab, $\mathrm{mgHA} / \mathrm{cm}^{3}$ ), the peripheral trabecular density adjacent to the cortex $\left(\mathrm{mgHA} / \mathrm{cm}^{3}\right)$, the central medullary trabecular density $\left(\mathrm{mgHA} / \mathrm{cm}^{3}\right)$, the ratio of peripheral to medullary trabecular bone density, and cortical BMD $\left(\mathrm{mgHA} / \mathrm{cm}^{3}\right)$ were measured. Bone microstructure including the trabecular bone volume fraction (BV/TV), trabecular number (Tb.N, 1/mm), trabecular separation ( $\mathrm{Tb} . \mathrm{Sp}, \mathrm{mm})$, inhomogeneity of the network $(\mathrm{mm})$, cortical thickness (Ct.Th, mm), cortical porosity (Ct.Po, $\%)$, cortical pore volume $\left(\mathrm{mm}^{3}\right)$ and cortical pore diameter $(\mathrm{mm})$ were analysed. Bone erosion was additionally documented in scans of the MCP and the proximal interphalangeal joints.

\section{Statistical analysis}

Data analyses were performed using SPSS software, V.19 (SPSS Inc., Chicago, Illinois, USA). The analysis's first step comprised descriptive statistical measures of sample characteristics. Subsequently, Kolmogorov-Smirnov and Shapiro-Wilk tests were carried out to verify the Gaussian distribution of the sampling means for the smallest group $(\mathrm{RA}[-])$. Differences among PsA, RA[+] and RA[-] were then determined either by Student's t test or the Mann-Whitney U test, depending on the test result for Gaussian distribution. In order to evaluate the relationships of demographic characteristics (ie, gender, age, disease duration and body mass index) and disease-related parameters (ie, ACPA/RF positivity, glucocorticoid treatment) with $\mathrm{BV} / \mathrm{TV}$ and TB.N, we set up two linear regression models-one for each of the aforementioned imaging parameters. All independent variables were included into the regression modelling by entering all variables at a single step. A dummy coding procedure was used in order to include multi-categorical variables properly. For the current mode of glucocorticoid therapy (categories: treatment with at least $7.5 \mathrm{mg} /$ day for at least 3 months, low-dose treatment with a maximum of $5 \mathrm{mg} /$ day for at least 3 months, no treatment) no treatment was chosen as the reference category, while for patient subgroups (categories: PsA, RA $[-]$ and RA[+]), PsA was designated as the reference. Both reference categories formed the largest subgroup with respect to the corresponding characteristics. Additionally, a forward and backward regression for BV/TV and Tb.N were performed. A p value of less than 0.05 was considered as statistically significant.

\section{RESULTS \\ Demographic and disease-specific characteristics of RA and PsA patients}

With respect to demographic parameters, such as age, height and body mass index, patients in the RA group were not different from the PsA group (table 1). For instance, the mean \pm SD age was $53.7 \pm 12.3$ years in the RA group and it was 50.5 \pm 13.1 years in the PsA group. Furthermore, the two groups were comparable in disease-specific variables such as disease duration (RA: 9.1 \pm 8.4 years, PsA: $6.9 \pm 7.3$ years), disease activity according to the DAS28 score (RA: $3.12 \pm 1.5$, PsA: $3.09 \pm 1.4$ ) and serum levels of $\mathrm{C}$ reactive protein. Also, modified HAQ scores were not significantly different between the two groups (table 1). ACPA and RF were found in $60 \%$ and $55 \%$ of RA patients, respectively. Both antibodies were found in $52 \%$ of the RA[-] and $82 \%$ of the $\mathrm{RA}[+]$ patients. None of the PsA patients showed a positive reaction for ACPA or RF. $38 \%$ of PsA patients had monoarticular or oligoarticular disease, and $62 \%$ had polyarticular disease. Daktylitis or a history of daktylitis was found in $24 \%$ of the PsA patients. Bone erosion was detected in $70 \%$ of the PsA patients and $72 \%$ of the RA patients. Non-traumatic fracture occurrence was similar in both groups.

With regards to antirheumatic therapy, the majority of patients received conventional or biological DMARD treatment, which was comparable between the RA and the PsA groups (table 1). The total number of previous and current DMARDs used in RA patients was higher than in PsA patients, most probably reflecting the higher abundance of effective drugs for RA as compared to PsA. Only few RA and PsA patients received glucocorticoid treatment at doses of more than $7.5 \mathrm{mg}$ prednisolon equivalent (less than 10\%). Use of low-dose glucocorticoid therapy was more frequent in RA (33\%) than in PsA (10\%). Six patients in the RA group received bisphosphonates, while none of the PsA patients did so (table 1).

\section{Comparison of bone microstructure in RA and PsA patients}

We first addressed whether the entire group of RA patients differed from PsA patients with respect to vBMD and bone microstructure. Surprisingly, no significant differences were found for $\mathrm{vBMD}$, including total BMD $\left(300 \pm 77\right.$ vs $\left.316 \pm 62 \mathrm{mgHA} / \mathrm{cm}^{3}\right)$, trabecular BMD $\left(152 \pm 46\right.$ vs $\left.165 \pm 40 \mathrm{mgHA} / \mathrm{cm}^{3}\right)$ and cortical 
Table 1 Patient characteristics

\begin{tabular}{|c|c|c|c|c|}
\hline & PsA & RA total & $\mathrm{RA}[+]$ & $\mathrm{RA}[-]$ \\
\hline \multicolumn{5}{|l|}{ Demographic characteristics } \\
\hline Patients N & 50 & 60 & 38 & 22 \\
\hline Gender (male/female) & $26 / 24$ & $27 / 33$ & $15 / 23$ & $12 / 10$ \\
\hline Age (years) & $50.5 \pm 13.1$ & $53.7 \pm 12.3$ & $51.9 \pm 12.7$ & $56.9 \pm 11.0$ \\
\hline Height $(\mathrm{cm})$ & $173.1 \pm 8.1$ & $171.4 \pm 11.0$ & $170.5 \pm 11.3$ & $173.1 \pm 10.4$ \\
\hline Weight $(\mathrm{kg})$ & $83.7 \pm 16.3$ & $76.1 \pm 19.6^{*}$ & $73.8 \pm 17.5^{*}$ & $80.8 \pm 23.2$ \\
\hline BMI & $27.7 \pm 5.0$ & $25.8 \pm 4.9$ & $25.3 \pm 4.2^{*}$ & $26.7 \pm 6.1$ \\
\hline \multicolumn{5}{|l|}{ Disease-specific characteristics } \\
\hline Duration of disease (years) & $6.9 \pm 7.3$ & $9.1 \pm 8.4$ & $10.6 \pm 8.3^{*}$ & $6.6 \pm 8.1$ \\
\hline Duration of psoriasis (years) & $20.3 \pm 14.4$ & NA & NA & NA \\
\hline ACPA-positive, N (\%) & $0(0)$ & $36(60)$ & $36(95)$ & $0(0)$ \\
\hline RF-positive, N (\%) & $0(0)$ & $33(55)$ & $33(87)$ & $0(0)$ \\
\hline ACPA-positive and RF-positive, N (\%) & $0(0)$ & $31(52)$ & $31(82)$ & $0(0)$ \\
\hline$C$ reactive protein (mg/L) & $4.3 \pm 6.6$ & $5.4 \pm 7.4$ & $5.7 \pm 8.4$ & $4.8 \pm 5.2$ \\
\hline Health assessment questionnaire (units) & $0.75 \pm 0.8$ & $1.04 \pm 0.7$ & $1.1 \pm 0.7$ & $0.80 \pm 0.7$ \\
\hline Disease activity score in 28 joints (units) & $3.09 \pm 1.4$ & $3.12 \pm 1.5$ & $3.46 \pm 1.6$ & $2.57 \pm 1.1$ ** \\
\hline Erosive diseaset, $\mathrm{N}(\%)$ & $35(70)$ & $43(72)$ & $27(71)$ & $16(73)$ \\
\hline Non-traumatic fractures, N (\%) & $6(12)$ & $6(10)$ & $6(16)$ & $0(0)$ \\
\hline \multicolumn{5}{|l|}{ Treatment modalities } \\
\hline Current DMARDs, N (\%) & $27(54)$ & $39(65)$ & $28(74)$ & $15(68)$ \\
\hline $\mathrm{N}$ of current and previous DMARDs & $1.02 \pm 0.8$ & $2.10 \pm 1.5^{*}$ & $2.37 \pm 1.5^{*}$ & $1.6 \pm 1.3$ \\
\hline Current biological therapies, N (\%) & $27(54)$ & $39(65)$ & $29(76)$ & $10(45)$ \\
\hline $\mathrm{N}$ of current and previous biological therapies & $1.24 \pm 1.7$ & $1.55 \pm 1.5$ & $1.9 \pm 1.5$ & $0.9 \pm 1.2^{* *}$ \\
\hline Current glucocorticoids $\ddagger$ N (\%) & $1(2)$ & $4(7)$ & $3(8)$ & $1(4.5)$ \\
\hline Current LD glucocorticoids§, N (\%) & $5(10)$ & $20(33)$ & $17(45)$ & $3(14)$ \\
\hline Current bisphosphonates, N (\%) & 0 & $6(10)$ & $6(16)$ & $0(0)$ \\
\hline \multicolumn{5}{|c|}{$\begin{array}{l}\text { Results are mean } \pm \text { SD or absolute values and percentage. } \\
\text { tErosive disease: at least one erosion at metacarpophalangeal joint, proximal interphalangeal joint, radius or ulna. } \\
\text { †Current glucocorticoids: } \geq 7.5 \mathrm{mg} \text { prednisolone for at least } 3 \text { months. } \\
\S \text { Current LD glucocorticoids: } \leq 5 \mathrm{mg} \text { prednisolone for at least } 3 \text { months. } \\
{ }^{*} \text { Significant differences from PsA, } p<0.05 \text {. } \\
{ }^{* *} \text { Significant differences from RA[+], }<<0.05 \text {. } \\
\text { ACPA, anticyclic citrullinated peptide antibody; BMI, body mass index; DMARD, disease-modifying antirheumatic drug; LD, low dose; RA, rheumatoid arthritis; RA[+], RA[-], } \\
\text { ACPA)-positive and/or rheumatoid factor-positive ACPA-negative and rheumatoid factor (RF)-negative RA; PSA, psoriatic arthritis. }\end{array}$} \\
\hline
\end{tabular}

BMD $\left(787 \pm 113\right.$ vs $\left.818 \pm 76 \mathrm{mgHA} / \mathrm{cm}^{3}\right)$ when comparing RA to PsA patients, respectively. Also, the parameters related to cortical and trabecular bone microstructure were not different between PsA and RA patients (table 2).

\section{Comparison of bone microstructure in RA[+] and PsA patients}

Based on recent findings on the importance of autoantibodies on bone, ${ }^{30}$ we decided to perform a separate analysis of $\mathrm{RA}[+]$ as well as RA[-]patients. $\mathrm{RA}[+]$ patients showed a significantly decreased total trabecular density $(\Delta 15.2 \%)$, meta-trabecular density $(\Delta 12.2 \%)$ and inner trabecular density $(\Delta 19.3 \%)$ compared to PsA patients. In addition, the BV/TV $(\Delta 14.6 \%)$ and the Tb.N $(\Delta 10 \%)$ were significantly decreased in $\mathrm{RA}[+]$ patients. Furthermore, a strong trend towards higher Tb.Sp and inhomogeneity of the network was found in $\mathrm{RA}[+]$ patients compared with PsA patients. No differences were detected in Ct.Th, cortical density or Ct.Po between the two groups (all data are shown in table 2). Representative HR-pQCT scans of PsA, $\mathrm{RA}[+]$ and $\mathrm{RA}[-]$ patients are presented in figure 1 .

\section{Comparison of bone microstructure in $\mathrm{RA}[+]$ and $\mathrm{RA}[-]$ patients}

Similar results were found when the $\mathrm{RA}[+]$ group was compared to the $\mathrm{RA}[-]$ group. $\mathrm{RA}[+]$ patients showed significantly decreased total trabecular density $(\Delta 17.9 \%)$, meta-trabecular density $(\Delta 14.2 \%)$ and inner trabecular density $(\Delta 25.1 \%)$ compared to $\mathrm{RA}[-]$ patients. Moreover, in $\mathrm{RA}[+]$ patients, BV/TV $(\Delta 18.8 \%)$ and Tb.N $(\Delta 14.2 \%)$ were significantly lower, and the Tb.Sp $(\Delta 27 \%)$ was significantly higher than in RA[-] patients. Again, the cortical bone parameters did not differ between $\mathrm{RA}[+]$ and RA[-] patients.

\section{Comparison of bone microstructure in $\mathrm{RA}[-]$ patients and PsA patients}

Conversely, no differences were found between RA[-] and PsA patients regarding vBMD, and trabecular and cortical bone microstructure parameters, indicating that $\mathrm{RA}[-]$ patients, unlike $\mathrm{RA}[+]$ patients, have a bone microstructure that is similar to that of PsA patients.

\section{Regression analysis}

The regression model for $\mathrm{BV} / \mathrm{TV}$ revealed significant relations to gender $(\beta=-0.32, \mathrm{t}=-3.56, \mathrm{p}=0.001)$, age $(\beta=-0.21$, $\mathrm{t}=-2.27, \mathrm{p}=0.025)$ and autoantibody positivity $(\beta=-0.24$, $\mathrm{t}=-2.28, \mathrm{p}=0.025)$ when RA patients were compared to PsA patients as a reference (see table 3 ). All of these characteristics were inversely related to the dependent variable, implying that male gender, younger age and the absence of autoantibodies were related to higher values of BV/TV. Very similar results were 
Table 2 High-resolution peripheral quantitative CT results

\begin{tabular}{|c|c|c|c|c|c|c|c|c|}
\hline & PsA & RA total & $\mathrm{RA}[+]$ & $\mathrm{RA}[-]$ & $\begin{array}{l}\text { p Value PsA } \\
\text { vs RA total }\end{array}$ & $\begin{array}{l}\text { p Value PsA } \\
\text { vs } R A[+]\end{array}$ & $\begin{array}{l}\text { p Value PsA } \\
\text { vs RA[-] }\end{array}$ & $\begin{array}{l}\text { p Value } R A[+] \\
\text { vs } R A[-]\end{array}$ \\
\hline \multicolumn{9}{|c|}{ Volumetric BMD (mg HA/cm³) } \\
\hline Total bone density & $315.8 \pm 61.7$ & $299.6 \pm 76.7$ & $292.0 \pm 78.9$ & $312.6 \pm 72.7$ & 0.230 & 0.116 & 0.849 & 0.320 \\
\hline Tb bone density & $165.1 \pm 40.3$ & $152.0 \pm 46.1$ & $140.0 \pm 44.2$ & $172.8 \pm 42.7$ & 0.120 & 0.007 & 0.465 & 0.007 \\
\hline Meta Tb bone density & $230.1 \pm 40.4$ & $214.4 \pm 43.6$ & $202.1 \pm 41.2$ & $235.6 \pm 40.2$ & 0.056 & 0.002 & 0.593 & 0.007 \\
\hline Inner Tb bone density & $120.2 \pm 43.2$ & $109.0 \pm 49.8$ & $97.1 \pm 48.8$ & $129.6 \pm 45.7$ & 0.216 & 0.021 & 0.407 & 0.014 \\
\hline Ratio: meta/inn [1] & $2.19 \pm 1.2$ & $2.26 \pm 1.0$ & $2.42 \pm 1.2$ & $2.00 \pm 0.7$ & 0.731 & 0.374 & 0.382 & 0.135 \\
\hline Ct bone density & $818.0 \pm 75.6$ & $786.7 \pm 113.5$ & $788.2 \pm 104.6$ & $784.0 \pm 130.1$ & 0.087 & 0.142 & 0.566 & 0.836 \\
\hline \multicolumn{9}{|l|}{ Microstructure parameters } \\
\hline BV/TV [1] & $0.137 \pm 0.03$ & $0.127 \pm 0.04$ & $0.117 \pm 0.04$ & $0.144 \pm 0.04$ & 0.122 & 0.007 & 0.463 & 0.007 \\
\hline Tb number $(1 / \mathrm{mm})$ & $2.02 \pm 0.30$ & $1.93 \pm 0.47$ & $1.82 \pm 0.51$ & $2.12 \pm 0.31$ & 0.252 & 0.044 & 0.210 & 0.008 \\
\hline Tb separation (mm) & $0.441 \pm 0.10$ & $0.507 \pm 0.30$ & $0.563 \pm 0.37$ & $0.411 \pm 0.08$ & 0.118 & 0.053 & 0.205 & 0.012 \\
\hline Inhomogeneity (mm) & $0.203 \pm 0.09$ & $0.231 \pm 0.13$ & $0.259 \pm 0.15$ & $0.183 \pm 0.06$ & 0.135 & 0.054 & 0.392 & 0.080 \\
\hline Ct. thickness (mm) & $0.800 \pm 0.19$ & $0.744 \pm 0.26$ & $0.743 \pm 0.26$ & $0.746 \pm 0.26$ & 0.233 & 0.269 & 0.346 & 0.980 \\
\hline Ct porosity (\%) & $2.5 \pm 1.2$ & $3.1 \pm 2.2$ & $2.8 \pm 1.7$ & $3.8 \pm 3.0$ & 0.134 & 0.388 & 0.352 & 0.586 \\
\hline Ct pore volume $\left(\mathrm{mm}^{3}\right)$ & $15.1 \pm 9.1$ & $17.0 \pm 12.8$ & $15.5 \pm 12.1$ & $20.3 \pm 15.2$ & 0.465 & 0.587 & 0.471 & 0.276 \\
\hline Ct pore diameter (mm) & $0.16 \pm 0.02$ & $0.16 \pm 0.02$ & $0.16 \pm 0.02$ & $0.16 \pm 0.02$ & 0.278 & 0.287 & 0.507 & 0.756 \\
\hline
\end{tabular}

found when performing a regression for $\mathrm{Tb} . \mathrm{N}$, revealing gender $(\beta=-0.19, t=-2.01, p=0.047)$ and autoantibodies $(\beta=-0.24$, $\mathrm{t}=-2.20, \mathrm{p}=0.030$ ) as the factors determining Tb.N (table 3). Furthermore, in the backward regression model, significant relationships were found between $\mathrm{BV} / \mathrm{TV}$ and gender $(\beta=-0.35$, $\mathrm{t}=-4.08, \mathrm{p}<0.001)$, and between $\mathrm{BV} / \mathrm{TV}$ and autoantibody positivity $(\beta=-0.23, t=-2.67, p=0.009)$. Similar results were found for Tb.N and gender $(\beta=-0.23, t=-2.46, p=0.016)$, and between Tb.N and autoantibody positivity $(\beta=-0.22$, $\mathrm{t}=-2.38, \mathrm{p}=0.019$; online supplementary table $\mathrm{S} 1$ ).

\section{DISCUSSION}

In this study, we demonstrate that $\mathrm{RA}[+]$ patients have a bone structure that is different from that of RA[-] patients and PsA patients. Despite similar demographic variables, disease duration and activity, and antirheumatic therapy, $\mathrm{RA}[+]$ patients displayed more severe deterioration of the trabecular bone structure than $\mathrm{RA}[-]$ patients and PsA patients. In contrast, RA[-] patients were indistinguishable from PsA patients with respect to $\mathrm{BMD}$, and trabecular and cortical bone structure. A multivariate logistic regression model supported the concept that the presence of autoantibodies, next to age and gender, is independently associated with trabecular bone loss and disturbed trabecular microarchitecture.

These data support the concept that $\mathrm{RA}[+]$ is a distinct disease entity and can be differentiated from $\mathrm{RA}[-]$ disease by its clinical presentation. It is already well known that the presence of autoantibodies such as ACPA and RF is associated with a higher risk for developing radiographic bone erosion. ${ }^{31} 32$ These lesions in the juxta-articular cortical bone result from direct exposure of the bone to synovial inflammatory tissue. In accordance with this observation, digital $\mathrm{x}$-ray radiogrammetry of the hand of RA patients showed more pronounced loss of $\mathrm{BMD}$ in $\mathrm{RA}[+]$ patients than in $\mathrm{RA}[-]$ patients. ${ }^{33}$ Moreover, mechanistic data suggest that ACPA directly induces osteoclast differentiation and bone resorption. ${ }^{30}$ These data are additionally supported by the very recent findings that the mere presence of ACPA is associated with bone loss before the onset of inflammatory disease. ${ }^{34}$ In addition, the presence of autoantibodies such as ACPA and RF could be associated with a higher burden of inflammation. Indeed, the trend towards higher levels of $\mathrm{C}$ reactive protein (CRP) and higher DAS28 and HAQ scores in $\mathrm{RA}[+]$ patients compared to $\mathrm{RA}[-]$ and PsA patients could further enhance the risk for developing bone loss in this subgroup of patients. Whether ACPA or RF plays a more pronounced role in triggering bone loss, however, remains to be determined. Given the overlap of ACPA and RF positivity, which was $82 \%$ in our population, the differential effects of ACPA and RF are not easy to determine. Based on the data by Harre and colleagues, ACPA can directly influence bone, which provides a mechanism of how autoantibody positivity can trigger enhanced bone loss. However, this observation does not exclude the role of RF and the role of binding of immune complexes to Fc receptors. Preliminary evidence in bone erosion analysis suggests that RF indeed represents an enhancer of bone loss in ACPA-positive but not ACPA-negative RA patients, but further research is needed to address the role of RF.

So far, trabecular bone architecture has been inadequately examined in patients with inflammatory arthritis. No study has been performed in PsA and only one study has been carried out in RA patients which focused on a subsegment of RA patients. Zhu and colleagues found that vBMD and BV/TV were decreased and trabecular inhomogeneity was increased in women with RA compared to those without RA. ${ }^{35}$ Although this study confirmed the notion that RA is associated with trabecular bone loss, the results can hardly be generalised based on the exclusive assessment of women, the lack of information about the autoantibody status and the fact that only a very few patients received biological drug therapy, which is now widely used for the treatment of RA and PsA patients in many countries. Furthermore, it is particularly interesting to compare RA and PsA patients with respect to trabecular bone structure, since these diseases share a chronic course but differ profoundly in their pathophysiology, for instance in their cytokines mediators apart from TNF. Moreover, RA and PsA are profoundly different with respect to periarticular bone architecture with many more bony proliferations in PsA than in $\mathrm{RA}^{26}$ 


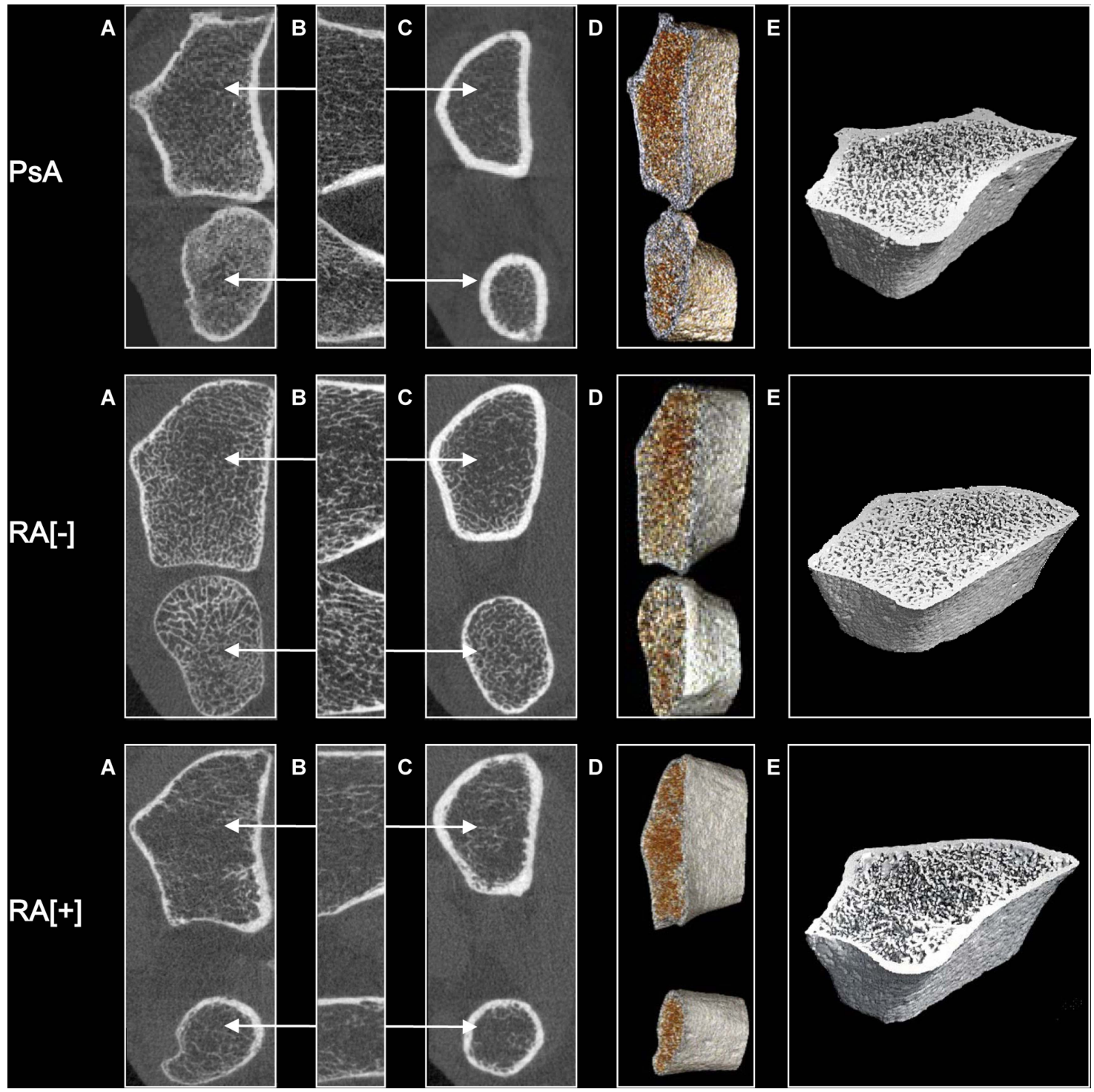

Figure 1 High-resolution peripheral quantitative CT scans of the distal radius (upper bone) and ulna (lower bone) of patients with psoriatic arthritis (PsA), seronegative rheumatoid arthritis (RA[-]) and seropositive rheumatoid arthritis (RA[+]). (A) Most distal slice, axial view; (B) total scan region of the 110 slices, coronar view; $(C)$ most proximal slice, axial view; $(D)$ three-dimensional (3D) reconstruction of the total scan region; (E) 3D reconstruction of the distal radius.

In the present study, trabecular vBMD and BV/TV were significantly decreased in $\mathrm{RA}[+]$ patients as compared to their RA[-] counterparts, as well as to PsA patients. Trabecular bone loss affected the central marrow region and the peripheral region adjacent to the cortical bone. Moreover, we assessed bone quality, since alterations of trabecular density and microstructure are associated with a higher risk for peripheral fractures. $^{36}$ Indeed, we found decreased Tb.N associated with higher Tb.Sp and inhomogeneity in $\mathrm{RA}[+]$ patients compared to their $\mathrm{RA}[-]$ counterparts and PsA patients. These data suggest that bone quantity and bone quality are decreased in RA $[+]$ patients.

Aside from the presence of autoantibodies, gender and age were the key factors determining bone structure in patients with RA and PsA, which supports the robustness of the analyses, as both factors strongly influence bone quantity and quality. Further research, however, is needed to better understand the interactions of the individual variables determining bone loss in patients with RA and PsA. For instance, it was stunning that despite the well- described negative effects of glucocorticoids on the skeleton, ${ }^{37}$ the use of low-dose glucocorticoids (5 $\mathrm{mg}$ prednisolone or less) positively rather than negatively influenced $\mathrm{Tb} . \mathrm{N}$. However, the most likely explanation for this finding is the anti-inflammatory effect of low-dose glucocorticoids, which counteracts inflammation-dependent bone loss and beneficially influences bone quality, as previously demonstrated by others. ${ }^{12} 38$

Cortical bone is a main component of bone strength. In peripheral sites, especially intracortical porosity in particular seems to play a crucial role in bone fragility. ${ }^{39}$ It was suggested that even small changes in Ct.Po more strongly affect bone stiffness than changes in the trabecular bone. ${ }^{40}$ Little is known about cortical bone changes in patients with RA apart from bone erosion and cortical bone loss in the phalangeal bones, as assessed by Dual-energy x-ray absorptiometry. ${ }^{41} \mathrm{Zhu}$ and colleagues reported that Ct.Po is increased in women with compared to those without RA. ${ }^{35}$ In our study we did not find major differences in cortical density, Ct.Th or Ct.Po among RA[+], $\mathrm{RA}[-]$ and PsA subjects, suggesting that cortical bone changes 
Table 3 Regression models of selected high-resolution peripheral quantitative CT parameters

\begin{tabular}{|c|c|c|c|c|c|c|}
\hline & \multicolumn{3}{|l|}{ BV/TV } & \multicolumn{3}{|l|}{ Tb.N } \\
\hline & $\boldsymbol{\beta}$ & $T$ & Sig. & $\beta$ & $T$ & Sig. \\
\hline Intercept & & 7.628 & 0.000 & & 8.373 & 0.000 \\
\hline Gender & -0.320 & -3.557 & 0.001 & -0.188 & -2.012 & 0.047 \\
\hline Age & -0.211 & -2.273 & 0.025 & -0.146 & -1.520 & 0.132 \\
\hline Duration of disease & -0.009 & -0.092 & 0.927 & -0.023 & -0.236 & 0.814 \\
\hline BMI & 0.055 & 0.0584 & 0.561 & 0.094 & 0.968 & 0.335 \\
\hline PsA vs RA seronegative & 0.106 & 1.113 & 0.268 & 0.123 & 1.245 & 0.216 \\
\hline PsA vs RA (RF-positive) & -0.110 & -1.198 & 0.234 & -0.191 & -2.010 & 0.047 \\
\hline PsA vs RA (ACPA-positive) & -0.081 & -0.881 & 0.381 & -0.072 & -0.753 & 0.453 \\
\hline $\begin{array}{l}\text { PsA vs RA (RF-positive and } \\
\text { ACPA-positive) }\end{array}$ & -0.239 & -2.281 & 0.025 & -0.239 & -2.202 & 0.030 \\
\hline No GC vs current GC & 0.086 & 0.936 & 0.351 & 0.116 & 1.218 & 0.226 \\
\hline No GC vs current $L D G C$ & 0.078 & 0.797 & 0.427 & 0.196 & 1.919 & 0.058 \\
\hline$R^{2}$ adjusted & & 0.190 & & & 0.130 & \\
\hline
\end{tabular}

Boldface type indicates statistically significant results ; type in boldface and italics indicates results that were significant by trend.

ACPA, anti-cyclic citrullinated peptide antibody; BV/TV, bone volume fraction; GC, glucocorticoids ( $\geq 7.5 \mathrm{mg}$ prednisolone for at least 3 months); LD GC, low dose glucocorticoids ( $\leq 5 \mathrm{mg}$ prednisolone for at least 3 months); Tb.N, trabecular number.

are shared by various different inflammatory joint diseases. On the other hand, we could find a trend towards lower Ct.Th in RA patients compared to PsA patients; Ct.Th was, in fact, lowest in $\mathrm{RA}[+]$ patients, suggesting that also cortical bone is affected by the autoimmune processes in RA patients.

In conclusion, these data show that $\mathrm{RA}[+]$ patients face the most profound changes in trabecular bone. 'RA' represents a mixed population with respect to bone composition and, if not stratified for autoantibody status, RA has a very similar trabecular BMD and micro-architecture to that of PsA. Our observations, as well as previous data, suggest that the impact of inflammation on bone is similar in RA and PsA. However, autoantibodies are an additional factor aggravating bone loss in arthritis. In fact, (1) the observation of occurrence of osteopenia very early in the disease course of RA, ${ }^{33}$ and (2) the detection of cortical bone changes in the periarticular bone of autoantibody-positive healthy individuals ${ }^{34}$ and the functional properties of ACPA to stimulate osteoclastogenesis ${ }^{30}$ all support the specific bone phenotype of $\mathrm{RA}[+]$ patients.

Acknowledgements The authors thank Tommy Vacca and Annemarie Kocijan for proofreading.

Contributors RK, SF and ME collected and analysed the data. RK, JR, SF and GS designed the study. RK and $G S$ wrote the manuscript. KE and JR, revised the manuscript.

Funding Roland Kocijan was supported by a postdoctoral research fellowship from the Bayerische Forschungsstiftung. This study was supported by the Deutsche Forschungsgemeinschaft (SPP1468-IMMUNOBONE), the Bundesministerium für Bildung und Forschung (project ANCYLOSS) and the TEAM and MASTERSWITCH projects of the European Union and the Innovative Medicines Initiative-funded project BTCure.

Competing interests None.

Ethics approval Local ethics committee University Erlangen-Nuremberg.

Provenance and peer review Not commissioned; externally peer reviewed.

\section{REFERENCES}

1 Mclnnes IB, Schett G. The pathogenesis of rheumatoid arthritis. N Engl J Med 2011:365:2205-19.

2 Gladman DD, Helliwell P, Mease PJ, et al. Assessment of patients with psoriatic arthritis: a review of currently available measures. Arthritis Rheum 2004:50:24-35.
3 Veale DJ. New therapies and new goals for psoriatic arthritis. Arthritis Rheum 2011;63:874-6

4 Gravallese EM, Manning C, Tsay A, et al. Synovial tissue in rheumatoid arthritis is a source of osteoclast differentiation factor. Arthritis Rheum 2000;43:250-8.

5 Ritchlin CT, Haas-Smith SA, Li P, et al. Mechanisms of TNF-alpha- and RANKL-mediated osteoclastogenesis and bone resorption in psoriatic arthritis. J Clin Invest 2003;111:821-31.

6 McGonagle D, Lories RJ, Tan AL, et al. The concept of a 'synovio-entheseal complex' and its implications for understanding joint inflammation and damage in psoriatic arthritis and beyond. Arthritis Rheum 2007;56:2482-91.

7 Schett G, Coates LC, Ash ZR, et al. Structural damage in rheumatoid arthritis, psoriatic arthritis, and ankylosing spondylitis: traditional views, novel insights gained from TNF blockade, and concepts for the future. Arthritis Res Ther 2011;13(Suppl 1):S4.

8 Ogata A, Kumanogoh A, Tanaka T. Pathological role of interleukin-6 in psoriatic arthritis. Arthritis 2012;2012:713618.

9 Baeten D, Breban M, Lories $\mathrm{R}$, et al. Are spondylarthritides related but distinct conditions or a single disease with a heterogeneous phenotype? Arthritis Rheum 2013;65:12-20.

10 Hardy R, Cooper MS. Bone loss in inflammatory disorders. J Endocrinol 2009;201:309-20.

11 Westhovens R, Nijs J, Taelman V, et al. Body composition in rheumatoid arthritis. $\mathrm{Br}$ J Rheumatol 1997;36:444-8.

12 Dirven L, van den Broek M, van Groenendael JH, et al. Prevalence of vertebral fractures in a disease activity steered cohort of patients with early active rheumatoid arthritis. BMC Musculoskelet Disord 2012;13:125.

13 Kim SY, Schneeweiss S, Liu J, et al. Risk of osteoporotic fracture in a large population-based cohort of patients with rheumatoid arthritis. Arthritis Res Ther 2010;12:R154.

14 Hoff M, Boyesen P, Haugeberg G, et al. High disease activity is a predictor of cortical hand bone loss in post-menopausal patients with established rheumatoid arthritis: a 5-year multicentre longitudinal study. Rheumatology (Oxford) 2010;49:1676-82.

15 El Maghraoui A, Rezqi A, Mounach A, et al. Prevalence and risk factors of vertebral fractures in women with rheumatoid arthritis using vertebral fracture assessment. Rheumatology (Oxford) 2010;49:1303-10.

16 Geusens P, Lems WF. Osteoimmunology and osteoporosis. Arthritis Res Ther 2011;13:242.

17 van Staa TP, Geusens P, Bijlsma JW, et al. Clinical assessment of the long-term risk of fracture in patients with rheumatoid arthritis. Arthritis Rheum 2006:54:3104-12.

18 Bultink IE, Vis M, van der Horst-Bruinsma IE, et al. Inflammatory rheumatic disorders and bone. Curr Rheumatol Rep 2012;14:224-30.

19 Frediani B, Allegri A, Falsetti $\mathrm{P}$, et al. Bone mineral density in patients with psoriatic arthritis. J Rheumatol 2001;28:138-43.

20 Grazio S, Cvijetic S, Vlak T, et al. Osteoporosis in psoriatic arthritis: is there any? Wien Klin Wochenschr 2011;123:743-50.

21 Pedreira PG, Pinheiro MM, Szejnfeld VL. Bone mineral density and body composition in postmenopausal women with psoriasis and psoriatic arthritis. Arthritis Res Ther 2011;13:R16.

22 van der Weijden MA, van der Horst-Bruinsma IE, van Denderen JC, et al. High frequency of vertebral fractures in early spondylarthropathies. Osteoporos Int 2012;23:1683-90.

23 Boutroy $\mathrm{S}$, Bouxsein $\mathrm{ML}$, Munoz F, et al. In vivo assessment of trabecular bone microarchitecture by high-resolution peripheral quantitative computed tomography. J Clin Endocrinol Metab 2005;90:6508-15.

24 Finzel S, Ohrndorf S, Englbrecht $M$, et al. A detailed comparative study of high-resolution ultrasound and micro-computed tomography for detection of arthritic bone erosions. Arthritis Rheum 2011;63:1231-6.

25 Stach CM, Bauerle M, Englbrecht M, et al. Periarticular bone structure in rheumatoid arthritis patients and healthy individuals assessed by high-resolution computed tomography. Arthritis Rheum 2010;62:330-9.

26 Finzel $\mathrm{S}$, Englbrecht $\mathrm{M}$, Engelke $\mathrm{K}$, et al. A comparative study of periarticular bone lesions in rheumatoid arthritis and psoriatic arthritis. Ann Rheum Dis 2011;70:122-7.

27 Fouque-Aubert A, Boutroy S, Marotte $\mathrm{H}$, et al. Assessment of hand bone loss in rheumatoid arthritis by high-resolution peripheral quantitative CT. Ann Rheum Dis 2010;69:1671-6.

28 Aletaha D, Neogi T, Silman AJ, et al. 2010 Rheumatoid arthritis classification criteria: an American College of Rheumatology/European League Against Rheumatism collaborative initiative. Ann Rheum Dis 2010;69:1580-8.

29 Rudwaleit M, Taylor WJ. Classification criteria for psoriatic arthritis and ankylosing spondylitis/axial spondyloarthritis. Best Pract Res Clin Rheumatol 2010;24:589-604.

30 Harre U, Georgess D, Bang H, et al. Induction of osteoclastogenesis and bone loss by human autoantibodies against citrullinated vimentin. J Clin Invest 2012;122:1791-802.

31 Morel J, Combe B. How to predict prognosis in early rheumatoid arthritis. Best Pract Res Clin Rheumatol 2005:19:137-46.

32 Vencovsky J, Machacek S, Sedova L, et al. Autoantibodies can be prognostic markers of an erosive disease in early rheumatoid arthritis. Ann Rheum Dis 2003:62:427-30. 


\section{Clinical and epidemiological research}

33 Boyesen P, Hoff M, Odegard S, et al. Antibodies to cyclic citrullinated protein and erythrocyte sedimentation rate predict hand bone loss in patients with rheumatoid arthritis of short duration: a longitudinal study. Arthritis Res Ther 2009;11:R103.

34 Kleyer A, Finzel S, Rech J, et al. Bone loss before the clinical onset of rheumatoid arthritis in subjects with anticitrullinated protein antibodies. Ann Rheum Dis 2014;73:854-60.

35 Zhu TY, Griffith JF, Qin L, et al. Structure and strength of the distal radius in female patients with rheumatoid arthritis: a case-control study. J Bone Miner Res 2013;28:794-806.

36 Szulc P, Boutroy S, Vilayphiou N, et al. Cross-sectional analysis of the association between fragility fractures and bone microarchitecture in older men: the STRAMBO study. J Bone Miner Res 2011;26:1358-67.
37 Canalis E, Mazziotti G, Giustina A, et al. Glucocorticoid-induced osteoporosis: pathophysiology and therapy. Osteoporos Int 2007;18:1319-28.

38 Haugeberg G, Strand A, Kvien TK, et al. Reduced loss of hand bone density with prednisolone in early rheumatoid arthritis: results from a randomized placebo-controlled trial. Arch Intern Med 2005;165:1293-7.

39 Zebaze RM, Ghasem-Zadeh A, Bohte A, et al. Intracortical remodelling and porosity in the distal radius and post-mortem femurs of women: a cross-sectional study. Lancet 2010;375:1729-36.

40 Burr DB. Cortical bone: a target for fracture prevention? Lancet 2010;375:1672-3.

41 Hoff $\mathrm{M}$, Haugeberg $\mathrm{G}$, Kvien TK. Hand bone loss as an outcome measure in established rheumatoid arthritis: 2-year observational study comparing cortical and total bone loss. Arthritis Res Ther 2007:9:R81. 


\section{Differences in bone structure between rheumatoid arthritis and psoriatic arthritis patients relative to autoantibody positivity}

Roland Kocijan, Stephanie Finzel, Matthias Englbrecht, Klaus Engelke, Juergen Rech and Georg Schett

Ann Rheum Dis 2014 73: 2022-2028 originally published online August 7, 2013

doi: 10.1136/annrheumdis-2013-203791

Updated information and services can be found at:

http://ard.bmj.com/content/73/11/2022

These include:

Supplementary Supplementary material can be found at:

Material http://ard.bmj.com/content/suppl/2013/08/07/annrheumdis-2013-2037 91.DC1.html

References This article cites 40 articles, 9 of which you can access for free at: http://ard.bmj.com/content/73/11/2022\#BIBL

Email alerting Receive free email alerts when new articles cite this article. Sign up in the service box at the top right corner of the online article.

Collections

Articles on similar topics can be found in the following collections

Immunology (including allergy) (5120)

Connective tissue disease (4236)

Degenerative joint disease (4622)

Musculoskeletal syndromes (4931)

Rheumatoid arthritis (3245)

\section{Notes}

To request permissions go to:

http://group.bmj.com/group/rights-licensing/permissions

To order reprints go to:

http://journals.bmj.com/cgi/reprintform

To subscribe to BMJ go to:

http://group.bmj.com/subscribe/ 